\title{
La Colonización del Chaco austral argentino y el tránsito hacia el ciclo algodonero. Afluencia humana y problemas de coexistencia en una sociedad en formación
}

\author{
Oscar Ernesto Mari \\ IIGHI-CONICET, Argentina
}

\begin{abstract}
Durante las décadas veinte y treinta del siglo pasado, se produjo en el entonces Territorio del Chaco un vertiginoso proceso que modificó radicalmente la fisonomía económica y social de este espacio argentino. Este proceso, que se conoció como el "ciclo algodonero", en distinción al inmediatamente anterior modelo de explotación denominado "ciclo forestal" o "taninero", se caracterizó por la incorporación de fuertes contingentes inmigratorios destinados a la colonización y a las tareas manuales que demandaba el cultivo y cosecha del textil. La problemática social derivada de esa afluencia humana, los conflictos de convivencia en los ámbitos rurales y las respuestas del Estado y la sociedad ante la cuestión, son objeto de análisis en el presente trabajo.

Palabras Clave: Conflictos sociales, espacio rural, Chaco.

During the twenty and thirty decades of the last century, a vertiginous process took place in the Territory of Chaco that radically modified the economic and social appearance of this Argentine space. This process, which was known as the "cotton cycle", in distinction to the immediately previous model of operation denominated "forest cycle" or "cycle of tannin", was characterized by the incorporation of important inmigratory contingents destined to the colonization and the manual tasks that the culture and harvests of the textile demanded. The social problems derived from this human affluence; the conflicts of coexistence in the rural scopes; and the answers of the State and the society about the question, are analysed in the present work.
\end{abstract}

KeYwords: Social Conflicts, Rural Space, Chaco.

\section{Introducción}

La problemática aquí planteada se desarrolló en un espacio geográfico que en determinada época fue uno de los "Territorios Nacionales" de la República Argentina. Recibieron esta denominación aquellas regiones que no llegaron a formar parte de las iniciales provincias constituidas y su pro- 
ceso de organización e incorporación al Estado demandó un considerable esfuerzo en el que se ensayaron diversas fórmulas y normativas para su configuración final.

El origen histórico de estos Territorios se remonta a las llamadas "Tierras Nacionales", que fueron motivo de disputas entre el Estado y las provincias a partir de 1862 . En ese año se dictó la ley n. ${ }^{\circ} 28$ por la cual se determinó que "Todos los Territorios existentes fuera de los límites de las provincias, son nacionales...". En el marco de una progresiva centralización estatal, se inició un proceso de definición de la propiedad de estos vastos espacios periféricos situados en el norte y sur de la nación, que se hallaban bajo dominio indígena y/o expuestos a las pretensiones de países vecinos. Desde entonces, la incorporación formal de estas jurisdicciones al dominio nacional se retrasó más de dos décadas en las que se alternaron campañas militares externas e internas, algunos desacuerdos limítrofes y distintas configuraciones ordenancistas que culminarían finalmente con la sanción de la ley orgánica de los Territorios Nacionales en 1884.

En el transcurso de este lapso de tiempo, el Estado argentino desplegó acciones de conquista militar, ocupación y poblamiento de estas tierras, algunas de las cuales se desarrollaron de forma simultánea. Se libró en el norte una desgastante guerra con el Paraguay en espacios geográficos que luego se convertirían también en Territorios Nacionales; y se ensayó un primer intento de organización política y administrativa para algunas de estas jurisdicciones, mediante la creación de las Gobernaciones de Chaco (1872), de la Patagonia (1878) y de Misiones en 1881, convirtiéndose estos ejemplos en los antecedentes más inmediatos de la norma definitiva que se sancionaría en 1884.

La ley n. ${ }^{\circ} 1532$ de este último año dispuso la institucionalización de los Territorios Nacionales bajo una organización más precisa, pero que demostraba en alguna medida la "transitoriedad" de esta condición, como paso necesario para su ulterior conversión en provincias. Por ella se creaban nueve unidades territoriales a las que se dotaba de un régimen político uniforme y una delimitación más precisa, con lo cual quedaba regularizada la situación institucional de estas jurisdicciones. ${ }^{1}$

Uno de los Territorios surgidos bajo esta nueva organización fue el "Chaco", aunque con límites más acotados, ya que la anterior Gobernación

1 Los Territorios Nacionales creados por la ley 1532 fueron: La Pampa, Neuquén, Río Negro, Chubut, Santa Cruz, Tierra del Fuego, Misiones, Formosa y Chaco 
creada con cierta premura en 1872, luego de finalizada la guerra con el Paraguay, fue dividida en dos unidades (Chaco y Formosa), con sus respectivas autoridades. Por ser precisamente éste nuestro ámbito de estudio, sus referencias merecen una atención más detallada.

La palabra "Chaco" es de origen quechua; ya era utilizada por los naturales al momento de la llegada de los españoles y originalmente aludía a una forma particular de caza practicada en la región. La misma dio nombre a una inmensa jurisdicción que comprendía parte de los actuales países de Bolivia, Paraguay y Argentina. Con el tiempo se fueron precisando mejor las subregiones que pasaron a conocerse como el Chaco Boreal, el Chaco Central y el Chaco Austral, que a menudo se confunde con el "Gran Chaco Argentino". Usualmente esta última designación involucraba al Este de las actuales provincias de Salta y Santiago, Norte de Santa Fe y la totalidad de las actuales Formosa y Chaco. El Chaco Austral, en cambio, abarca un espacio algo menor - desde el río Bermejo hacia el sur- y éste es, desde luego, el espacio geográfico que nos ocupa en términos generales.

A diferencia de otras regiones del país, el proceso de incorporación efectiva de estas tierras al dominio nacional (una vez resuelta la frontera externa), demandó un esfuerzo algo mayor debido a las peculiaridades de su geografía y al carácter guerrero de sus pueblos originarios. Con la mayor parte de su superficie cubierta por una impenetrable vegetación, y habitado por parcialidades indígenas nómadas y hostiles a la civilización blanca, los intentos de conquista, evangelización y poblamiento habían fracasado repetidamente desde la época hispánica, permaneciendo el área casi infranqueable durante casi trescientos años. De hecho, desde los tiempos coloniales la comunicación terrestre entre el ámbito Rioplatense y el Paraguay se hacía por la mesopotamia argentina, dada la imposibilidad de realizarla por el Chaco debido al belicismo de los nativos.

A la sazón, y en buena medida por tales motivos, el Chaco sería el último espacio territorial en ser controlado e incorporado enteramente al Estado, lo cual no se lograría hasta trascurridas las dos primeras décadas del siglo XX. De esta forma, el proceso de ocupación y poblamiento "blanco" chaqueño se realizó en etapas que transcurrieron entre las dos últimas décadas del siglo XIX y las dos primeras del siguiente, en movimientos que avanzaron hacia el interior (centro-oeste) mediante sucesivas campañas militares de sometimiento de los indígenas, construcción de líneas férreas troncales y políticas de fomento a la colonización agrícola. 
Paralelamente a este proceso se fue mutando también el aliciente económico que hacía atractiva la empresa de conquista de este territorio, transitándose de una fase forestal-extractiva que caracterizó a la primera etapa de poblamiento (1878-1920), a otra agrícola-industrial a partir de esa última década. Al mismo tiempo, y en parte como consecuencia de este cambio de ciclo, se modificó también la composición, origen y cantidad de la población, hasta tal punto que en determinado momento se identificó al Chaco como un "crisol de razas", producto de las diferentes corrientes inmigratorias recibidas.

La ampliación de la frontera agrícola a partir de los años veinte, el cambio en el ciclo económico con la irrupción del cultivo algodonero como exitoso motor del poblamiento y la modalidad intensiva de la colonización, conformarían en el Chaco un panorama socio-económico muy peculiar que lo distinguiría de los demás territorios nacionales. La conjunción de una afluencia inmigratoria de características aluviales que arribó a un espacio periférico feraz y alejado de los centros de decisión y las limitaciones de un esquema político y administrativo local para atender la tumultuosa expansión que generó el auge algodonero, gestarían en poco tiempo un conjunto de problemas que el Estado no pudo afrontar en tiempo y forma. Algunas dificultades surgidas durante este singular proceso, particularmente las que conciernen a la conflictividad originada en los espacios rurales como consecuencia de la masiva afluencia humana, la percepción de esta problemática por parte de los sectores dirigentes y la sociedad en general, y el papel desempeñado por el Estado como garante del orden social, pretenden ser los puntos básicos de análisis en el presente trabajo.

En las páginas subsiguientes, se procurará explicar la evolución del proceso de poblamiento en el Chaco desde las últimas décadas del siglo XIX hasta el primer tercio del siglo XX, indicándose las áreas en donde se llevó a cabo cada movimiento y marcando su asociación con los respectivos ciclos económicos que obraron como estímulo para las respectivas etapas colonizadoras. Simultáneamente se hará una breve referencia al régimen político que tuvieron los Territorios a partir de su organización en 1884 para entender la situación de minoría en la que quedaron sus habitantes y explicar de este modo las limitaciones existentes para la solución de sus carencias.

Nos detendremos luego en el análisis de lo que significó para el Chaco el cultivo algodonero, particularmente en su dimensión socioeconómica, y en este sentido prestaremos especial atención a los problemas sociales que 
supuso la efervescencia de este auge, particularmente en los espacios rurales, en donde se concentró la masa humana que periódicamente llegó atraída por las posibilidades laborales.

Finalmente, al tiempo que se intentará escrutar la "sensibilidad" de esta sociedad en formación frente a problemáticas sociales no siempre expuestas, se analizará también el papel del Estado como tutor de este proceso y las medidas instrumentadas para garantizar el control social en un período de desbordante expansión.

\section{La ocupación del espacio, el poblamiento y la transición hacia el ciclo algodonero}

Una vez definida la frontera con el Paraguay luego del laudo arbitral del presidente de Estados Unidos Rutherford Hayes en 1878, por el cual se fijó al río Pilcomayo como límite entre ambos países, quedó despejado el camino para iniciar la ocupación plena y el poblamiento del Chaco Central y Austral por parte del Estado Argentino. El objetivo implicaba la utilización masiva del ejército - esta vez para consolidar la frontera interna-, una inicial etapa de colonización oficial en las cercanías de los grandes ríos del Este (Paraná y Paraguay), el perfeccionamiento de la organización política y administrativa de esta jurisdicción y un posterior avance hacia sus espacios interiores.

Precisamente en ese año (1878) arribaron los primeros colonos Friulanos que se instalaron en el sitio que luego se convertiría en la capital del Chaco Austral (Resistencia) y en zonas aledañas, dando comienzo así a la primera etapa de colonización en el área oriental. Sería sin embargo la sanción de la ley 1532 de 1884 de organización de los Territorios Nacionales, la que formalizaría el inicio de la vida institucional del Chaco al definirse de manera más precisa su jurisdicción y dotarlo de sus correspondientes autoridades, en coincidencia con lo que ocurría simultáneamente con los demás Territorios del país. Por dicha ley se separó al Chaco Austral del (desde ahora) Territorio de Formosa (Chaco Central) y además se le redujeron sus límites, procedimiento éste que se repetiría — siempre en beneficio de las provincias vecinas - hasta 1915, en que adquiere su delimitación definitiva.

Si bien las iniciales colonias de inmigrantes que consolidaron la ocupación en el área oriental no tuvieron un auge inmediato, propiciarían una 
importante valorización de las tierras circundantes y, consecuentemente, cierto frenesí por acentuar el reparto, venta o arrendamiento de la tierra pública, lo cual llevó a la ejecución de prácticas poco juiciosas en el proceso.

En el afán de consolidar la ocupación, durante el periodo que trascurrió hasta el primer lustro del siglo XX, el Estado adjudicó unos 15 millones de hectáreas en inmensas fracciones cuyas superficies no eran inferiores a las 8.000 hectáreas. Uno de los ejemplos más paradigmáticos de este tipo de operación fue el caso de la compañía La Forestal, de capitales británicos, a la que le fueron otorgados más de 2 millones de hectáreas. Como consecuencia de ello se formó en la región "una corona" de latifundios destinados básicamente a la explotación forestal, que rodeó a los iniciales emplazamientos de colonización y que, en cierta forma, obstruyó la continuidad inmediata del primigenio (y más racional) sistema.

Si bien las nuevas leyes dictadas luego de la crisis de 1890 buscaron corregir estos excesos y aplicar una nueva política de adjudicaciones mucho más restrictiva que comenzaría a tener efecto a principios del siglo $\mathrm{XX}$, para ese momento el cuadro de situación demostraba que una importante porción de las tierras del sureste y sur del Chaco eran latifundios que estaban en manos privadas, desvirtuándose así, en parte, el propósito inicial de lograr un poblamiento equilibrado para este espacio. La explotación del quebracho colorado para la obtención de tanino contribuyó a afirmar el latifundio en este periodo, puesto que esta actividad practicada únicamente en gran escala, era por entonces el más fuerte atractivo para la ocupación de la tierra en un medio virgen e inhóspito.

En estas grandes superficies operaron unas pocas empresas que paulatinamente fueron acaparando el control de la actividad extractiva. Mediante "enclaves", como obrajes y fábricas de tanino, situados en el interior profundo y aislado de los controles estatales, llegaron a concentrar casi todos los rubros de explotación y comercialización de la actividad forestal, efectuando acuerdos sobre precios o directamente absorbiendo a pequeñas empresas competidoras. Algunos casos, como por ejemplo la anteriormente mencionada La Forestal Company, o Las Palmas del Chaco Austral, se erigieron en verdaderos núcleos industriales diversificados que propiciaron asientos poblacionales en sus inmediaciones, todos ellos directamente dependientes de estas empresas, y en donde no era posible residir ni comerciar sin autorización de las mismas. Si bien el funcionamiento de estas grandes compañías facilitó el surgimiento de pueblos vinculados a la 
actividad y demandó una considerable mano de obra, el sistema de explotación e industrialización imperante no tuvo un gran efecto dinamizador en la economía zonal, ya que de los insumos requeridos, pocos eran los productos provistos desde este medio.

Este periodo, que desde el punto de vista socio-económico fue denominado ciclo forestal, comenzaría su declinación - aunque con intermitentes repuntes- cuando terminaba la década del diez, por diversos factores concurrentes: la disminución de la demanda mundial debido a la sustitución del tanino por otros curtientes, el progresivo reemplazo del cuero por materiales sintéticos y, a escala regional, el crecimiento de los costos de producción por agotamiento de bosques, la mayor distancia entre los obrajes y las fábricas y otras causas que se agregarían más tarde en deterioro de las ganancias. El resultado de esta situación fue el progresivo cierre de fábricas, la clausura de obrajes con la consecuente desocupación de la mano de obra y el ocaso de pueblos ligados a la actividad.

Esas grandes propiedades despojadas de su riqueza forestal no recibieron reinversiones pero acogieron sin embargo a una ganadería primitiva en campos poco adecuados para ese fin y, si bien la actividad forestal continuó funcionando en el Territorio durante las décadas siguientes, ya no tendría el mismo impacto en la economía y demografía regional. Dicho papel lo cumpliría desde este momento un "nuevo ciclo" vinculado a la producción algodonera, en otra área geográfica del Chaco, y con particularidades distintas al proceso anterior.

Lo que se conoce como la segunda etapa colonizadora en el Chaco, que normalmente está asociada al cultivo de algodón, y que comenzó a mostrarse con toda claridad a principios de la década del veinte, es un proceso que en realidad tiene sus orígenes en el primer lustro del siglo XX, y para su correcta comprensión, se hace necesario distinguir sus distintas fases.

Disminuido el impulso de la primera etapa de la colonización oficial en la zona oriental, y comprobado el despropósito de la dispendiosa política de adjudicaciones de grandes extensiones a concesionarios o empresas que le sucedió, a partir de 1907 se retomó el concepto de crear colonias (pastoriles y mixtas) de superficies moderadas y fiscalizadas por el Estado. Incidió en esta nueva modalidad la sanción de la ley n. ${ }^{\circ} 4167$ de 1903 que disponía la exploración, mensura y determinación de la capacidad económica de las tierras, antes de su entrega a los particulares. Las primeras colonias creadas con este mecanismo serían ubicadas en el sector noreste y orientadas hacia el río Bermejo. 
Esta renovada iniciativa colonizadora, si bien favoreció la llegada de un frente pionero que elevó de 21.000 a 43.000 el número de habitantes del Chaco entre 1905 y 1912, fue netamente nacional en tal periodo, con contingentes provenientes mayoritariamente de la vecina provincia de Corrientes que no tuvieron relación con el cultivo algodonero, puesto que éste se hallaba aún en etapa de ensayo y otras actividades suscitaban mayor interés, como las forestales o las vinculadas al cultivo de la caña de azúcar, por ejemplo.

Pero en 1908 se dictó la ley 5559, llamada de "fomento de los Territorios Nacionales", que, en el caso específico del Chaco, tendría sin duda una importancia decisiva. Por la misma se autorizaba la construcción de ramales ferroviarios troncales que atravesarían esa región desde el sureste hacia el centro, suroeste y noroeste; y también la venta de la tierra fiscal circundante para amortizarlos. Esto perseguía un triple objetivo: adentrarse en el corazón del Territorio intercomunicándolo con las vecinas provincias de Salta y Santiago; valorizar la tierra fiscal a la vera de las vías para sufragar con su venta los costos del ferrocarril y, al mismo tiempo, explotar los bosques vírgenes en beneficio del fisco, básicamente mediante la extracción de durmientes.

El tendido de rieles comenzó en 1909 y para 1914 la obra estaba terminada. Simultáneamente, una nueva campaña del ejército rastrilló el interior del Territorio sometiendo o reduciendo a los grupos indígenas que aún no se habían asimilado al dominio blanco, de modo tal que para 1915, la totalidad de la superficie se hallaba ya bajo control del Estado. En el espacio ganado se iniciaba un proceso de ocupación civil (generalmente espontánea en esta etapa) y un conjunto de pueblos y parajes surgían en los alrededores de las estaciones ferroviarias, espaciadas calculadamente cada cierto número de kilómetros.

La conquista del Chaco estaba así concluida; la misión del ejército terminada (se replegó en 1917) y la frontera agrícola definitivamente ampliada, con el único límite que le imponían los inmensos montes nativos. ${ }^{2}$ Solamente restaba dar un nuevo empuje a la colonización organizada para consolidar el poblamiento, lo cual se concretaría de manera formal a partir del decreto presidencial del 11 de julio de 1921.

Por el mismo se libraron más de un millón de hectáreas a la colonización agrícola, creándose un conjunto de colonias en el centro y sudoeste y previendo un régimen de adjudicación de la tierra más justo y acotado que,

2 En Argentina se llama "monte" a la vegetación cerrada nativa, propia de los lugares semiáridos. 
aunque en la práctica se demostraría burocratizado y excesivamente lento, resultaría al cabo más controlado que en las etapas anteriores.

En este preciso momento se presentaban condiciones inmejorables para el poblamiento exitoso del interior del Chaco. El precio del algodón en los mercados internacionales aumentaba considerablemente y el área agrícola recientemente incorporada reunía condiciones óptimas para su cultivo. Estaba abierta la entrada a la inmigración extranjera y se disponía de una flamante red ferroviaria capaz de sacar la producción hacia los puertos fluviales. La demanda de fibra continuaría su incremento en los años subsiguientes debido a la disminución de la producción algodonera de Estados Unidos como consecuencia de la plaga del picudo (1922), por lo cual un proceso colonizador basado en esta actividad tenía el éxito asegurado.

Este es el momento en el que se advierte una modificación fundamental en la fisonomía económico-social del Chaco y puede hablarse con propiedad de un cambio de ciclo. Si bien la actividad extractivo-forestal otrora floreciente nunca desaparecería, desde 1918 se había iniciado un período declinante y, aunque gozó de algunos repuntes temporales, ya no volvería a tener la importancia que tuvo en las décadas anteriores. La fuerza que adquirió el cultivo algodonero y sus efectos dinamizadores, permiten marcar aproximadamente en esta época, una "transición" entre el llamado "ciclo forestal" o del tanino, y el nuevo "ciclo algodonero".

Ello, desde luego, traería modificaciones trascendentales en todos los órdenes de la vida en este Territorio, cuyos verdaderos alcances serán debidamente apreciados en el transcurso del presente trabajo. En lo que respecta específicamente al algodón como producto fundamental de las transformaciones que se sucederían, debe decirse que en el Chaco, por ensayos previos, ya se tenía un conocimiento preciso sobre las enormes potencialidades de este cultivo. Se había comprobado que la latitud, clima y régimen de lluvias - especialmente en algunas zonas - resultaban las ideales para su desarrollo.

Ya desde 1904 hubo algunos incentivos oficiales para producir algodón en el Chaco, como distribución gratuita de semillas y folletos explicativos, por ejemplo, pero su cultivo no arraigó lo suficiente por el mayor interés que suscitaban las actividades forestales y por falta de estímulos en los precios.

Los factores anteriormente enunciados y la disponibilidad de mano de obra - liberada como consecuencia de la declinación de la actividad taninera- propiciarían a comienzos de los años veinte el contexto necesario 
para pasar de una economía extractiva a una productiva, sustentable y con mayores efectos multiplicadores.

La oportuna política inmigratoria incentivó la entrada de nuevos contingentes pobladores — esta vez extranjeros—, que provinieron fundamentalmente de la Europa del Este. En esta nueva oleada colonizadora arribaron al Chaco unos 16.000 inmigrantes europeos entre 1923 y 1930, y unos 4.200 se agregarían más tarde, entre los años 1931y 1936. ${ }^{3}$ Estos "gringos"4 fueron los que se distribuyeron entre las quince colonias creadas tras el decreto de 1921 en las tierras ganadas del centro y oeste del Territorio. Allí es donde floreció la actividad algodonera que daría identidad al nuevo ciclo que se iniciaba vigorosamente.

En este periodo, y a diferencia de las etapas anteriores, el minifundio caracterizó la ocupación del espacio fiscal del interior del Chaco, ya que se asignaron parcelas que promediaron las 50 hectáreas, tamaño por entonces suficiente para explotaciones de tipo familiar. El apogeo del cultivo ocurrido entre la segunda mitad de la década del veinte y la totalidad de la siguiente generó un paisaje agrario muy peculiar donde todo giraba en torno al algodón. La periódica afluencia de braceros para carpida y cosecha dinamizaba el comercio y, por su propia lógica, la actividad demandó distintos servicios y propició a su vez un proceso de industrialización primaria que se concentró básicamente en el desmotado de los capullos y la fabricación de aceite con su semilla. La instalación de desmotadoras, empresas de acopio, industrias aceiteras y casas comerciales de ramos generales fue exponencial y la cadena de servicios en función de esta producción se multiplicó considerablemente.

Los catorce años transcurridos desde 1920 hasta 1934 cambiarían la fisonomía económica y demográfica del Chaco. De 60.500 habitantes se pasa a 214.000 en este periodo y para 1936 se calculaban ya en 314.000, registrándose así el crecimiento poblacional más alto de todas las jurisdicciones argentinas en la época. De este modo y en pocos años, el llamado "oro blanco" convirtió al Chaco en una de las jurisdicciones más prósperas de la Argentina, atrayendo con su dinámica a miles de inmigrantes internos y externos y a emprendedores de diversos oficios que deseaban encontrar un futuro prometedor en este paraíso productivo. A raíz del ciclo algodone-

3 No se consideran aquí los numerosos inmigrantes provenientes de países vecinos, que se instalaron en áreas geográficas distintas a las de los europeos y ejercieron diferentes actividades laborales.

4 En Argentina, especialmente en los ámbitos rurales, se llama genéricamente "gringos" a quienes poseen piel blanca y cabello rubio, y la palabra no tiene ningún contenido despectivo. 
ro, el Chaco se convirtió en principal productor a nivel nacional y adquirió una identidad distintiva que preservaría a lo largo de varias décadas.

No obstante, el vértigo de este proceso y la continua atracción humana que su propio éxito generó, serían, a su vez y simultáneamente, los precipitadores de problemas que las autoridades locales o nacionales no alcanzaron a resolver en tiempo y forma. El desborde de la estructura administrativa y de servicios causado por la extraordinaria afluencia de pobladores y trabajadores temporeros fue una constante y los esfuerzos por adaptarla a un cambiante escenario socioeconómico que se modificaba año tras año, serían decididamente insuficientes o, en el mejor de los casos, ineficaces.

Cabe analizar en tal sentido si las fuerzas del Estado estuvieron a la altura de un proceso que las propias autoridades centrales se empeñaron en estimular, pero cuya dimensión terminó excediendo sus posibilidades de controlador. Debe ponderarse asimismo en qué medida incidieron las voluntades políticas de turno para la neutralización, perdurabilidad —o profundización- de ciertas problemáticas, o las restricciones de una legislación de Territorios, cuyo incumplimiento adicional seguramente influyó en las limitaciones para sobrellevar este fenómeno de colonización intensiva.

Al respecto debe recordarse que la ley 1532 de organización de los Territorios Nacionales colocó a estos espacios bajo un ceñido tutelazgo estatal, lo cual implicaba que sus autoridades eran designadas por el Poder Ejecutivo Nacional y que sus habitantes tenían derechos civiles pero carecían de derechos políticos, salvo aquellos que podían ejercerse en los municipios constituidos. Se suponía que esta tutoría garantizaba al gobierno central un control absoluto sobre la evolución de estas jurisdicciones y su paulatina, gradual (y pacífica) inserción en la vida nacional.

De esta forma, durante esta etapa institucional — que en el caso del Chaco se mantuvo desde 1884 hasta 1951-, la administración descansó sobre un gobernador que dependió directamente del Ministerio del Interior y duraba tres años en el ejercicio de sus funciones. Era nombrado por el Poder Ejecutivo con acuerdo del Senado y estaba encargado, como autoridad superior del Territorio, de velar por el cumplimiento de las leyes y disposiciones nacionales. A las órdenes del gobernador se hallaba la policía territorial y un limitado plantel administrativo que se incrementó o disminuyó según la época, o bien de acuerdo a las características de gestión de cada gobernante. De todos modos, en general las funciones de esas autoridades fueron más de gestión que de resolución y sus decisiones estuvieron casi siempre sujetas a la aprobación del Ministerio del Interior. 
Si bien en la ley 1532 estuvieron previstas modificaciones a este restrictivo régimen, a medida que se fueran dando ciertos progresos económicos y sociodemográficos, las mismas no pudieron hacerse efectivas y sólo se cambió este esquema cuando se produjo la provincialización de estos Territorios en la década de los cincuenta.

Así pues, durante la mayor parte del periodo Territoriano, los habitantes de estas jurisdicciones estuvieron reducidos a una condición de ciudadanos de "segunda categoría", o fueron "nominales", como los define Ruffini, ${ }^{5}$ lo cual en la práctica significó desatenciones, omisiones o indolencia por parte del Estado Nacional frente a los distintos problemas que aquejaron a estas sociedades nuevas.

Las restricciones de la legislación o su incumplimiento, la lejanía de los centros de decisión y la oscilante atención de las autoridades centrales en la conducción del proceso, la minoría política de los ciudadanos de los Territorios y la falta de autonomía de la dirigencia local, son elementos que necesariamente deben ser tenidos en cuenta para comprender algunos aspectos de las cuestiones aquí planteadas.

\section{La problemática social derivada de la afluencia humana durante el ciclo algodonero}

Si bien algunos párrafos precedentes permiten suponer que el ciclo algodonero representó para el Chaco un período expansivo y de beneficios extendidos, sobre todo si se observa el exponencial incremento demográfico que se propició en un período muy breve, no deberían sin embargo dejar de mostrarse también las sombras de este "fulgor del Desierto Verde". ${ }^{6} \mathrm{Su}$ iridiscencia no ha podido ocultar, ni en la propia época, las máculas derivadas de una afluencia masiva de inmigrantes nacionales y extranjeros que desbordó reiteradamente a la administración territorial y a las previsiones mejor calculadas por las autoridades centrales.

La historiografía mundial suele exhibir con suficiencia las consecuencias de los abruptos procesos de colonización masiva en torno a la incorpo-

5 Ruffini, Martha: La pervivencia de la República Posible en los Territorios Nacionales. Poder y ciudadanía en Río Negro, Universidad Nacional de Quilmes, Buenos Aires, 2007.

6 "Desierto verde": frase acuñada por José Alumni para nombrar al Territorio del Chaco. "Fulgor del Desierto Verde" ha sido una frase usada por el historiador chaqueño Guido Miranda, aunque se emplee aquí para definir un floreciente periodo del Chaco en esa época. La misma se impone como título en una de las obras de Miranda, Fulgor del Desierto Verde. 1925-1947, Editorial Región, Resistencia, 1985, pág. 8. 
ración de nuevos territorios, hallazgos de yacimientos, o explotaciones temporalmente muy rentables: falta de infraestructura o su desborde en caso de que la hubiera; ausencia o imposibilidad de aplicar regulaciones; desapego a la ley; violencia; abusos y, consecuentemente, conflictos sectoriales o de convivencia. Los propios, en fin, de la presión humana de frentes pioneros que procuran su espacio vital en el ámbito a explotar; los inherentes, al cabo, a sociedades en vías de formación.

Tal vez los más conocidos ejemplos en este sentido sean - por la difusión de la literatura y la cinematografía—, los procesos ocurridos en el oeste de Estados Unidos y Alaska, o en Brasil, durante las "fiebres" del caucho $\mathrm{y}$ del oro.

En el caso del Territorio del Chaco, la etapa de ocupación del espacio agrícola y aún la que transcurre durante la consolidación del ciclo algodonero, ofrece algunas similitudes con los procesos antes señalados, aunque desde luego con las particularidades propias de un ámbito geográfico distinto, de una colonización dirigida y de componente multiétnico, y lógicamente en función de una explotación renovable que permitía un afincamiento poblacional duradero.

La nómina de consecuencias no deseadas, o problemas derivados de este vertiginoso proceso productivo, es suficientemente amplia como para abordarla en el estrecho marco de un artículo, pero en todo caso debe recordarse que uno de los rasgos más distintivos de la historia del Chaco, especialmente durante su época como Territorio Nacional, ha sido precisamente la precaria coexistencia entre las distintas etnias y grupos sociales que conformaron esta sociedad nueva.

La conflictividad de grupos humanos heterogéneos, de distintas culturas y contrapuestos intereses que procuraban progreso, espacio o supervivencia en un escenario cambiante y febril, se manifestó a través de diversas formas que respondieron a diversas causas, pero se desarrolló fundamentalmente en el ámbito rural, en donde estuvo radicada la mayor parte de la población en esa época, y en donde también la insuficiencia de los controles, la incomunicación, la dureza de las condiciones de vida, e incluso las particularidades del medio natural, facilitaron en buena medida los conflictos de carácter social.

De hecho, la literatura y hasta la cinematografía han plasmado este clima de efervescencia y hasta de zozobra en algunos momentos, al abordar temas, eventos o sucesos que por su virulencia, repetición, permanencia o espectacularidad, terminaron trascendiendo el espacio regional, gene- 
rando una imagen negativa de esta jurisdicción durante varias décadas. Aún durante los períodos de mayor esplendor de este Territorio, para la sociedad nacional en general la palabra "Chaco" se asociaba inmediatamente a la de "salvajismo" y llevó mucho tiempo revertir esta imagen.

Independientemente del ciclo o la actividad económica a la que estuvieron vinculados, pueden recordarse episodios que han dejado su huella en la memoria colectiva nacional y que son casi indefectiblemente asociados a la historia del Chaco Territoriano. Están todavía hoy muy presentes conflictos sociales violentos como los ocurridos en la localidad de Las Palmas (agosto de 1920); los de La Forestal, a comienzos de 1921, que, aunque acontecidos en el extremo norte de la provincia de Santa Fe, por distintas razones repercutieron fuertemente en este Territorio; los de Napalpí en 1925 (todos ellos con resultado de numerosas víctimas fatales); los problemas agrarios de 1934 y 1936; y menos graves, aunque también de larga duración, los conflictos de los obreros industriales en el Gran Resistencia a principios de la década de los cuarenta. ${ }^{7}$

7 Entre fines de 1919 y la mayor parte de 1920 hubo un fuerte estado de conflictividad entre los obreros y la parte patronal del ingenio Las Palmas, ubicado en la localidad homónima de Chaco. Este ingenio, tal como han coincidido varios autores, era "un Estado dentro del Estado"; una Compañía de capitales británico-argentinos con 2000 trabajadores en donde las condiciones laborales eran tan extensas como opresivas, se pagaban bajos sueldos en vales y no era posible comprar mercaderías fuera de la propiedad, ni ejercer el comercio sin autorización de la empresa. En diciembre de 1919 hubo allí un paro exitoso, en el que los trabajadores consiguieron acortar la jornada laboral y el cobro de haberes en moneda nacional. Sin embargo, en mayo de 1920, la Compañía inició una contraofensiva de control obrero con ayuda de miembros de la entonces "Liga Patriótica". Luego de varios incidentes (huelgas y enfrentamientos aislados) el conflicto se agudizó produciéndose un sangriento choque entre obreros y fuerzas de la empresa y la "Liga" entre el 9 y el 10 de agosto de ese año, con decenas de víctimas. El enfrentamiento culminó el 20 de agosto, luego de la intervención del ejército. Posteriormente, a comienzos de 1921, se repitieron similares incidentes, y casi por los mismos motivos, en otra de las grandes Compañías enclavadas en el Chaco, La Forestal, de capitales británicos, monopolizadora de la actividad taninera en Chaco y norte de Santa Fe, y con una estructura productiva y laboral similar a la de Las Palmas. Precisamente en los pueblos del norte de esta provincia ligados a la actividad de la empresa, se produjeron huelgas y choques entre obreros y la policía privada de la Compañía y agentes de la "Liga Patriótica". Dichos conflictos fueron descritos por la literatura histórica y recreados en el film "Quebracho", entre otras muestras. Entre 1924 y 1925 se repitieron - por motivos esencialmente laborales- enfrentamientos aislados entre indígenas de la Reducción de Napalpí y colonos inicialmente, y policías luego, en el interior del Chaco. Los sucesos conocidos como "La matanza de Napalpí"culminaron con cerca de doscientos aborígenes ejecutados por parte de las fuerzas policiales, en un hecho que hasta la actualidad continúa siendo debatido. Con respecto a los conflictos agrarios de la década del 30, también de fuerte repercusión extraregional, se hará una breve alusión en notas posteriores. La bibliografía sobre estos temas es bastante amplia y variada, pero una buena síntesis de esos conflictos puede hallarse en Mc Gee Deutsch, Sandra: Contrarevolución en la Argentina 1900-1932. La Liga Patriótica Argentina, Universidad Nacional De Quilmes, Buenos Aires, 2003; Cordeu, Edgardo Jorge y Siffredi, Alejandra: De la Algarroba al Algodón. Movimientos Milenaristas del Chaco Argentino, Juárez Editor, Buenos Aires, 1971. 
Podrían añadirse además, aunque por otros motivos $-\mathrm{y}$ por lo general desarrollados con sordina-, aquellos vinculados a la posesión de la tierra en áreas asignadas a la colonización; o los derivados de la ausencia o deficiencias del control estatal, como por ejemplo los producidos por la inseguridad (en su amplio espectro), o los conflictos de convivencia entre la masa laboral en obrajes y algodonales. ${ }^{8}$

De toda esta nómina, precisamente estos últimos son tal vez los que menor atención han recibido pese a que el caudal informativo ofrece posibilidades de encarar un análisis, por ejemplo, respecto a las consecuencias que producía, en términos de agitación social, la masiva incorporación de trabajadores temporeros y el particular frenesí de la cosecha algodonera durante los meses que transcurrían desde enero a julio. Sin duda este tema constituye una parte insoslayable de la problemática social del Chaco en esta época y por ello merece una pesquisa que, al tiempo que se describe el contexto económico y demográfico de este espacio, posibilite explicar los problemas puntuales que surgieron, especialmente en el ámbito rural, en determinados estratos de esta sociedad en formación.

Desde luego, los problemas específicos que en cierta forma se han preanunciado fueron derivados directamente del modo en que se realizaban las tareas relacionadas con el cultivo y la recolección del algodón y, ya por entonces, se suscitaron distintas opiniones entre los representantes de la dirigencia local respecto a los criterios con que debía encararse el control o solución de los mismos.

Como es de suponer, las labores inherentes al cultivo (carpida) y recolección del algodón en el Chaco fueron íntegramente manuales hasta años recientes. Ello requería periódicamente la incorporación de fuertes contingentes de braceros para ser destinados a estas faenas que, por ejemplo, para la campaña 1935-1936 (apogeo del ciclo), involucró a 129.639 trabajado-

8 Si bien, como se ha dicho al comienzo, la colonización del interior del Chaco tuvo un carácter direccional, la acción del Estado en materia de distribución de tierras fue deficiente e inconstante. La lentitud en mensurar y conceder la tierra pública hizo que vastas extensiones fuesen ocupadas "de hecho" por los colonos pioneros. Tal precariedad, que en buena parte de los casos se mantuvo durante años, ocasionó no pocas disputas entre los colonos; entre éstos con ganaderos provenientes de provincias limítrofes — también intrusos-, y obviamente con las comunidades indígenas originarias que intentaban frenar el avance de los blancos sobre su espacio vital. Por otra parte, debe anticiparse que durante la década del treinta, y a consecuencia de la intensa circulación de capitales, la deficiente estructura de seguridad y de vías de comunicación y un medio geográfico propiciante, se registró en el Chaco un fenómeno conocido como "bandolerismo rural", que se mantuvo vigente por varios años y llegó a hacer colapsar el sistema de seguridad del Territorio. 
res. ${ }^{9}$ Inicialmente, esta demanda se cubrió con mano de obra local —en buena medida indígenas pacificados-, pero la insuficiencia numérica de los nativos y la casi continua ampliación de la superficie cultivada exigió el complemento de trabajadores que provinieron espontáneamente o incentivados por los gobiernos locales o nacionales, de provincias como Corrientes, Santa Fe, Salta o Santiago, o de países vecinos, como Paraguay.

Sólo a título de ejemplo, para 1935 los requerimientos extraordinarios (es decir, extra-locales) calculados por el gobierno territorial para la cosecha de ese año hablaban de unas 30.000 personas y, en efecto, ingresaron para la zafra 29.407 braceros. $^{10}$ Teniendo en cuenta que la población permanente del Territorio ascendía entonces a 276.343 habitantes, esta afluencia significaba elevar repentinamente en casi un $11 \%$ el número de personas residentes en el Chaco.

Pero no sólo llegaban braceros en tales periodos; temporalmente arribaba también lo que el historiador Guido Miranda catalogó como "un ejército" de viajantes, comisionistas, vendedores y pagadores de todos los rubros, que buscaban tomar su porción en este tiempo de bonanza.

El movimiento y alternancia que provocaba el auge algodonero ha sido cuantificado especialmente a través de registros portuarios y ferroviarios y, al margen de las diferencias que pueden discutirse, se ha estimado, por ejemplo para los años 1934, 1935 y 1936, en 122.000, 165.000, y 299.000 respectivamente y en cifras redondas, el número de personas que "transitaron" por este Territorio, es decir, los números totales de ingresos y egresos. Debe advertirse que en cada uno de estos movimientos periódicos, siempre quedaba un remanente de personas que se afincaban aquí. ${ }^{11}$

Estos bruscos cambios demográficos provocaban naturalmente el desborde de la administración territorial, lo cual se evidenciaba de manera más nítida en la incapacidad del Estado para ejercer un adecuado control social. El componente medio que integraba la masa de cosecheros "golondrina" y sus precarias condiciones de residencia, constituían el germen de conflictos de convivencia en los que la fuerza pública - por distancia, insuficiencia o incompetencia—, pocas veces podía mediar.

9 Datos tomados del Censo Algodonero de la República Argentina, 1935-1936. Ministerio de Agricultura. Junta Nacional del Algodón. Buenos Aires, 1936, pág 88.

10 Cifras consignadas en la Memoria de Gobierno del gobernador José Castells correspondiente al año 1935. Establecimiento Tipográfico Juan Moro, Resistencia, 1937, pág. 93.

11 Por ejemplo, en el año 1936 entraron al Territorio por distintas vías 299.414 pasajeros y salieron 267.613, quedando por lo tanto un saldo favorable de 31.801 personas en el Chaco. Datos tomados de la Memoria de Gobierno de José Castells, correspondiente a 1936, pág. 84. 
El periodo de cosecha algodonera implicaba entonces, especialmente en las áreas ligadas a esta producción, una efervescencia económica y social difícilmente observable - al menos en esta época- en otras regiones del país. La frenética actividad, la circulación de dinero y el trajín humano otorgaban a pueblos y colonias la imagen de bulliciosas colmenas en las que transacciones, regateos y disputas, formaban parte de la postal.

El relato fidedigno de un historiador chaqueño contemporáneo ilustra elocuentemente el ritmo febril de este proceso al comentar sus circunstancias dentro de Sáenz Peña, la ciudad más importante vinculada a la producción algodonera:

\begin{abstract}
"En tiempos de cosecha, la estación del ferrocarril se hacina de "cosecheros" santiagueños y correntinos, que acampan en la "playa" convertida en una bolsa de colocaciones, a cargo de colonos que tratan de obtener el concurso de los braceros y de llevarlos de inmediato a la chacra. Es pintoresca la disputa cuando escasea la mano de obra, entre los tratantes de parla tan difícil...Las calles se atestan de camiones, volantas, sulkys, caballos, en los alrededores del Banco, las cooperativas y las casas de ramos generales; los carruajes deben colocarse en varias hileras, entre las cuales han de moverse con prolijidad de hormigas por imperceptibles hilillos de espacio. En las fondas, una humareda olorosa de frituras, tabaco y alcohol se mezcla con el tumulto de voces, fanfarronadas, risas y pendencias, como en las posadas de madera del "Far West" cinematográfico ... Los almacenes y las tiendas deben cerrar sus puertas varias veces al día, para atender la clientela que en ciertos momentos colma las dependencias, y renovar de hora en hora el público ... ${ }^{12}$
\end{abstract}

Idéntico panorama podía observarse, aunque a escala reducida, en los demás pueblos ligados al algodón en épocas de cosecha.

Sin embargo, y como directa consecuencia de este movimiento y de la masiva afluencia humana se elevaban también, y exponencialmente, los porcentajes de pleitos entre las personas. La fricción cotidiana en los espacios laborales, el hacinamiento en los sitios de alojamiento, las frecuentes disputas por los precios de las "provistas" y en los pesajes del algodón, ${ }^{13}$ la disponibilidad de dinero, la proliferación de lugares y espontáneas formas

12 Miranda, Guido: Tres Ciclos chaqueños (Crónica Histórica Regional). Editorial del Norte Argentino, Resistencia, 1980, págs. 253-254.

13 La "provista" era el conjunto de mercaderías — generalmente comestibles- que el propietario de la chacra suministraba semanal o quincenalmente a los braceros luego de comprarlas en el pueblo o paraje más cercano. El valor de las mismas -sobrecargado normalmente en un $25 \%$ o $30 \%$ - se descontaba en el momento en que el cosechero entregaba su recolección para el pesaje, también en básculas del propietario del algodonal. 
de esparcimiento, la circulación de bebidas alcohólicas. el cansancio acumulado de extenuantes jornadas y las limitaciones institucionales para ejercer un adecuado control social, eran factores combinados que potenciaban los conflictos de convivencia. ${ }^{14}$

Los mismos, seguramente contenibles dentro de un adecuado marco de control social, se desarrollaban sin embargo en entornos rurales, lejos de las autoridades y/o de voluntades mediadoras. El brazo "protector" del Estado no llegaba hasta los lugares más apartados del interior profundo del Territorio.

De esta forma, mínimos roces o diferencias de opinión en estos ámbitos aislados, transitaban casi inexorablemente el camino hacia un desenlace violento: las lesiones o la muerte de las personas implicadas en una contienda. De ahí que entre los problemas más comunes que se dieron en el ámbito rural en lo referido a conflictos de convivencia, se destaquen dentro de los primeros lugares, las agresiones físicas con lesiones, y los homicidios, sin desestimar desde luego al abuso sexual que, aunque frecuente, es difícilmente evaluable ya que aunque existen registros, sus datos no pueden ser concluyentes por ser éste un delito no siempre denunciado, y menos en esa época con la carga de prejuicios que suponía para las víctimas.

En cuanto a los principales motivos de estos problemas, independientemente de sus resultados finales y teniendo en cuenta los factores anteriormente descritos, deben añadirse además tres elementos adicionales: la naturaleza del componente social involucrado, el entorno laboral y la permisividad existente de poder llevar armas.

El componente medio de jornaleros, agricultores y braceros estaba integrado, como es de suponer, por las clases más bajas de la escala social. En el caso de los braceros, aún el "profesional" de la recolección, llamado "golondrina" porque alternaba en las zafras de diferentes regiones del país, era normalmente analfabeto o semianalfabeto, ${ }^{15} \sin$ instrucción adecuada

14 En el informe elaborado entre 1939 y 1940 por Rafael García Mata y Rómulo Franchelli como representantes de la Junta Nacional del Algodón, uno de los argumentos usados para promover el desarrollo de la mecanización de la cosecha algodonera residió en que ello “...evitaría la explotación del bracero adventicio, germen permanente de disturbios sociales como consecuencia de su lamentable condición económica...". (Cosecha Mecánica del Algodón, Estudio preparado por los Ingenieros Agrónomos Rafael García Mata y Rómulo Franchelli, Ministerio de Agricultura, Junta Nacional del Algodón, Buenos Aires, 1942, pág. 12).

15 Según el informe Mata-Franchelli, Cosecha Mecánica del Algodón, pág. 15, “el $60 \%$ de los cosecheros era analfabeto, no habiendo pasado el tercer grado los alfabetos". 
respecto al conocimiento de las leyes y cuyo respeto al "orden" se basaba más bien en el temor que inspiraba una autoridad "visible", que en su autocontrol. Eran personas curtidas, acostumbradas a las privaciones de la vida itinerante y sin hogar fijo.

No obstante, el grueso de esta masa humana no venía al Chaco a buscar pleitos, sino a una posibilidad de supervivencia por un plazo de cuatro o cinco meses. Usufructuaba los pasajes en ferrocarril costeados por el gobierno, alquilaba su fuerza laboral y la de su familia al mejor postor y luego alternaba de chacra en chacra levantando los capullos. En éstas, se alojaba donde podía, en el mejor de los casos en un galpón o granero en el que se hacinaba con otras familias, con la intimidad preservada únicamente mediante divisorias hechas con bolsas arpilleras. ${ }^{16}$ Esta promiscuidad constituía el germen de conflictos que estallaban a la primera ocasión y que se presentaban generalmente los fines de semana, días feriados o festivos.

La concurrencia a bailes, kermeses, juegos o reuniones espontáneas en algún "patio" o paraje cercano, el consumo de alcohol y la alteración de las emociones propiciaban inexorablemente pendencias y ejecución de venganzas. Una mirada provocadora o la menor diferencia de opiniones derivaba en un pleito y este desembocaba casi siempre en la agresión física. Las discusiones, riñas por ebriedad, juego o disputas sentimentales fueron moneda corriente en el contorno semicivilizado del Chaco rural, como lo testimonian los partes diarios policiales de la época. Las lesiones y homicidios eran en general una consecuencia natural de estas escaramuzas, ya que la mayoría de las personas portaba armas blancas o de fuego. El Código Rural lo autorizaba explícitamente en su artículo n. ${ }^{\circ} 253$, y esta disposición —oportunamente discutida y revisada - facilitó sin dudas la comisión de delitos de sangre. ${ }^{17}$ Este hábito, normalizado a través de las

16 Bolsa de yute comúnmente usada en el campo argentino para almacenamiento.

17 El Código Rural establecía en su artículo n. 253 que, "la policía no podrá prohibir o restringir el derecho de llevar armas, y en consecuencia, ninguna persona será registrada con el objeto de averiguar si lleva armas consigo...". Pero aclaraba en el artículo n. ${ }^{\circ} 254:$ "Es prohibido sin embargo hacer ostentación de armas o llevarlas a la vista, bajo pena de 10 pesos de multa.". Código Rural para los Territorios Nacionales. Recopilación realizada por Máximo Reyna, 1902-1910. Ministerio del Interior, Buenos Aires, 1910. En 1918 se intentó reformar el Código Rural y se puso especial énfasis en la reconsideración de estos artículos. En el proyecto de reforma se explicaba que, "dado el despoblamiento que existe en los territorios nacionales, no nos ha parecido prudente prohibir la portación de armas en la campaña, pero sí en los lugares poblados. El código actual no hace diferencia alguna sobre el particular, sin duda porque cuando se sancionó, había un número muy reducido de pueblos en los territorios..." (Memoria del Ministerio del Interior 1919-1920, inédita, pág. 338). 
letras del cancionero popular regional, ${ }^{18}$ se mantenía vivo además por la inducción publicitaria ejercida desde los periódicos locales, en donde aparecían regularmente avisos ilustrados de armas de fuego en los que se incitaba a su adquisición para resguardar la integridad personal.

Las cuestiones de honor se lavaban con sangre y en este sentido cabe destacar que las venganzas por conflictos previos fueron causa de un importante porcentaje de homicidios. Los partes policiales de entonces referidos a homicidios suelen comúnmente encabezar la información diciendo:"...por resentimientos anteriores se enfrentaron..., y en el hecho se produjo la muerte de uno de los contendientes...", lo cual reflejaba que la antigua práctica de los duelos por honor se mantenía vigente, aunque en los ámbitos rurales, la acción era espontánea y sin las formalidades de rigor.

De hecho, y si cabe el ejemplo, pese a las prohibiciones, esta práctica se mantuvo esporádicamente en el Chaco - y en los ámbitos urbanoshasta principios de la década del cuarenta, y entre personas que no estaban precisamente faltas de instrucción. ${ }^{19}$

La permisividad en la libre circulación de armas constituyó sin duda el principal factor desencadenante de hechos de sangre, a tal punto que en las estadísticas oficiales, entre las principales causas de muerte por motivos

18 La música popular denominada "litoraleña", en razón de que su ámbito de difusión (y nacimiento) es el litoral argentino (espacio lindante a los grandes ríos Paraná y Uruguay) y cuya máxima expresión es el ritmo bailable en pareja llamado "Chamamé", es la que penetró rápidamente entre las clases bajas del Chaco por la periódica afluencia de jornaleros provenientes de la vecina provincia de Corrientes. Esta música se halla hoy muy vigente — sobre todo en los ámbitos rurales_ - y a menudo sus letras se centran en la defensa del honor y la dignidad, los cuales deben preservarse - según los dictados-, poniendo en juego la propia vida en la satisfacción de una ofensa. El "culto nacional al coraje", oportuna y certeramente identificado por Juan Agustín García en su libro La Ciudad Indiana, se halla perfectamente expuesto en este género musical de la Argentina.

19 El Código de Policía de 1908 había legislado en su artículo n. ${ }^{\circ} 270:$ "Luego que se tuviere noticias de estarse concretando un duelo, el funcionario que corresponda, procederá a la detención del provocador y a la del retado, si éste hubiere aceptado el desafío, y no serán puestos en libertad, hasta que bajo palabra de honor, ofrezcan desistir de su propósito...”(Código de Policía para los Territorios Nacionales, Imprenta de Juan Alsina, Buenos Aires, 1908, pág. 49). Sin embargo, existe constancia de que esta práctica continuó en vigencia al menos hasta bien entrada la década del cuarenta, tanto a nivel local como nacional. De hecho, deben recordarse los comentados duelos de armas (con padrinos) entre el general Baldasarre y el coronel Pilotto en el campo de aviación de El Palomar, en abril de 1932; el de Pinedo y Lisandro De la Torre, en julio de 1935; y el de los doctores Álvarez Ahumada y Agustín Dillón, en Resistencia en abril de 1939, sin víctimas en todos los casos. (Archivo Histórico de la Provincia del Chaco, en adelante AHPCH, Diario La Voz del Chaco, en adelante LVCH, 11 de abril de 1932; 18 de julio de 1935 y 13 de abril de 1939). Fuentes del año 1942, registran a nivel local la permanencia de esta práctica, como puede observarse en el incidente ocurrido entre el secretario de la Gobernación del Chaco, Dr. Carlos Franco, y periodistas del periódico NORTE, a quienes el primero desafió a una "reparación por las armas" por una denuncia en su contra publicada en este medio. (AHPCH, Diarios LVCH y El Territorio, del 8 de octubre de 1942). 
constatables, figura en primer lugar la bronconeumonía, seguida de la tuberculosis; en tercer lugar la muerte producida por armas de fuego, y en cuarto lugar, la producida por heridas de arma blanca. ${ }^{20}$

El problema alcanzó tal gravedad en determinado momento, que el gobernador José Castells (1933-1938) se propuso limitar el derecho de portar armas, por cuanto entendía que para los tiempos que corrían eran innecesarias las licencias que concedía el Código Rural, y estaba probado que esto implicaba excesos que terminaban casi siempre en hechos de sangre. ${ }^{21}$ Este gobernador se concentró además en otro punto, que consistía en tratar de prevenir los desórdenes y riñas en el interior del Territorio, si tener que aumentar por ello los recursos policiales..$^{22}$ Desde años anteriores se obser-

20 En 1934, de 2.544 decesos totales en el Chaco, excluyendo el renglón señalado como "sin asistencia médica", puede observarse la siguiente escala en cuanto a las causas principales: bronconeumonía (233 casos); tuberculosis pulmonar (171 casos). Los fallecidos por herida de armas de fuego (incluyendo los accidentes) fueron 156, mientras que los muertos por heridas de arma blanca fueron 64. Entre estas dos últimas causas se encuentra el síncope cardíaco, con 132 casos. (Memoria de Gobierno de Castells, año 1934, pág. 150). En 1935, entre 3.213 decesos y excluyendo los 525 consignados como "sin asistencia médica", los fallecidos a consecuencia de heridas de armas de fuego pasan al segundo lugar, con 165 casos, luego de la bronconeumonia que causó 246 muertes. En este año, los fallecimientos por heridas de arma blanca suman 79 casos. (Memoria de Gobierno de Castells, año 1935, págs. 5051). En 1936, entre 3.309 defunciones, aunque no se detallan específicamente las causas de muerte, en la Memoria de Gobierno de este año figuran 370 casos producidos por "causas externas", es decir - y según el propio documento-, decesos producidos mayoritariamente por heridas de armas de fuego y blancas.(Memoria de Gobierno de Castells, año 1936, pág. 77).

21 En vista de las alarmantes estadísticas, el gobernador Castells se dirigió al jefe de la policía de la capital federal en estos términos: "La gobernación del Territorio Nacional del Chaco se propone solicitar del Poder Ejecutivo, la adopción de medidas destinadas a restringir el abuso que importa la portación de armas que autoriza el Código Rural sancionado en 1894, y que ya no responde a las necesidades de los mismos... a fin de documentar ampliamente las medidas que habrán de proponerse y con el propósito de estudiar las reglamentaciones existentes al respecto en la capital federal, es que me permito solicitar a ud., todas las disposiciones vigentes sobre portación de armas, rogando por razones de premura sirva ordenar que el envío se lleve a cabo a la mayor brevedad" (AHPCH, Copiadores de la secretaría de la gobernación del Chaco. Gobernador José Castells. 26 de enero de 1934)

22 Debe decirse en este sentido que el reclamo de los gobernadores del Chaco para incrementar la cantidad de agentes policiales, su equipamiento y capacitación, fue una constante desde la creación misma de la policía del Territorio en 1885, como también lo fueron las reticencias de las autoridades centrales para acceder a esta requisitoria. De manera recurrente se invocaron restricciones presupuestarias para las denegatorias, y de hecho se redujo sistemáticamente el número de agentes desde 1926 y durante buena parte de la década del treinta, paradójicamente cuando mayor fue la afluencia humana y también mayor el aporte rentístico del Chaco al erario público. Cabe añadir al respecto que durante la mayor parte de la época territoriana los agentes policiales carecieron de estabilidad, cobertura social, escuelas de formación y códigos claros de procedimientos, por lo cual la institución policial, además de ser deficiente en número y funciones (especialmente en los ámbitos rurales), estuvo permanentemente cuestionada por la opinión pública debido la venalidad y a los excesos de sus componentes. La organización y funcionamiento de las fuerzas de seguridad en el Chaco es tratada con mayor amplitud en: Mari, Oscar: "Inseguridad y Bandidaje en el Territorio Nacional del Chaco 19171940". Cuaderno de Geohistoria Regional n. ${ }^{\circ}$ 30, Resistencia, 1994. 
vaba en las estadísticas que casi la totalidad de las peleas y homicidios se producían los sábados en los boliches y bailes del interior, especialmente como consecuencia del desenfreno en el consumo de bebidas alcohólicas.

Por ello se puso en marcha una campaña en donde se impondría el sistema del "sábado inglés", por el cual se prohibía la apertura de locales ese día, como también la venta de bebidas alcohólicas en kermeses, bailes y clubes. ${ }^{23}$ Estas medidas se complementaban además con la prohibición de carreras de caballos, riñas de gallos, juegos de taba y naipes. Pero esto no podía ser más que una buena intención, sencillamente porque el Chaco no contaba con infraestructura policial para ejercer estos controles, y porque además, los mismos agentes transgredían las normas, como puede comprobarse en la documentación oficial y periódicos de la época.

Remarcando el análisis del entorno laboral, la observación de los registros ofrece datos reveladores respecto a los ámbitos en donde se producían estos hechos, como también acerca de las categorías sociales involucradas. Por ejemplo, para 1934, en que por primera vez se realizan estadísticas confiables al respecto, se contabilizan 167 homicidios en el Chaco sobre un total general de 533 delitos contra las personas en ese año. Las cifras revelan que la mayoría de los casos se produjeron entre los meses de enero a julio, es decir el período de zafra algodonera, donde la afluencia de cosecheros era mayor. Allí se tienen los picos más altos, con 26 muertes en el mes de mayo, mientras que en septiembre ocurrieron sólo cuatro. En 1935 el total de homicidios se eleva a 230, y en 1936 alcanza su pico máximo de 238 casos. $^{24}$ De ellos, 186 y 194 hechos respectivamente, fueron cometidos por trabajadores rurales.

23 El 1. ${ }^{\circ}$ de diciembre de 1933, el gobernador Castells se dirigió al ministro del Interior don Leopoldo Melo con el fin de solicitarle que "se disponga extender en los territorios nacionales los beneficios de la ley 11.640 (sábado inglés)"; ya "que habiéndose aplicado con anterioridad en breves períodos $(*)$, además de las ventajas generales que evidenció, tiene el excepcional efecto de provocar una enorme disminución de los delitos de sangre en el territorio"., y continúa diciendo que "Corresponde remarcar aquí que la estadística demuestra que en el Chaco los hechos de sangre se han venido produciendo especialmente los días sábados en los boliches del interior, como se demuestra con las planillas agregadas; la clausura de éstos negocios los días sábados ha impedido las reuniones que terminan casi siempre en pendencias cuchilleras, con la consiguiente alteración del orden", (AHPCH, Copiadores de la secretaría de la gobernación, Gobernador Castells. 1. ${ }^{\circ}$ de diciembre de 1933, pág.113).

(*) Se aplicó durante la gestión del gobernador Vrillaud en 1932.(Copiadores de la Secretaría de la gobernación, del 8 de abril de 1932, folio n. 206 y del 9 de mayo de 1932).

24 Para este año (1936) la población permanente del Chaco estaba calculada en 314.000 habitantes. Sólo para brindar una referencia en las cifras, debe decirse que en la actualidad (2008) el Chaco posee un millón de habitantes, y un homicidio de una persona común, aunque acontezca en el ámbito rural, sale titulado casi indefectiblemente en la primera plana de los diarios locales debido a su carácter casi excepcional. 
De la misma manera, el mapa de los homicidios revela que los mismos se cometieron en las áreas circundantes a los centros algodoneros más importantes, como Sáenz Peña y Quitilipi por ejemplo. A su vez, el $82 \%$ de estos homicidios (en promedio redondeado de estos tres años) fue cometido por jornaleros y peones, lo cual confirma que este tipo de delito se producía como directa consecuencia del tumultuoso frenesí de la cosecha y de la fricción cotidiana de la masa humana involucrada en esta actividad..$^{25}$

Cabe preguntarse en este momento en qué medida esta problemática constituía una real preocupación para la sociedad local y el gobierno.

En primer lugar debe señalarse que el estado de conflictividad social en los ámbitos rurales, concretamente en lo que desembocaba en delitos contra las personas, no tenía por entonces la trascendencia que en la actualidad le otorgan a estos episodios los medios de difusión. De hecho, los medios gráficos del Chaco no contaban en aquella época con un apartado destinado específicamente a lo que hoy se conoce como "sección policiales". La información sobre hechos delictivos aparecía indistintamente en cualquiera de las páginas de los periódicos, mezclada con noticias de otra índole, y en tales casos, refiriéndose preferentemente a los delitos cometidos contra la propiedad (cuatrerismo, hurtos, robos individuales o en banda, etcétera).

Pocas referencias existían respecto a delitos contra las personas (hechos de sangre, violaciones, incestos, raptos, estupros, etcétera), y cuando se aludía a este tipo de delitos, la información generalmente se circunscribía a episodios ocurridos en ámbitos urbanos, siempre y cuando su relevancia o la de los protagonistas involucrados, mereciese su publicación. Sólo en raras oportunidades podían encontrarse noticias de esta índole referidas a los ámbitos rurales, y en estos casos, se las presentaba de manera general y escueta, sin individualizaciones ni caracterización de los hechos; con un lenguaje de eufemismos, y casi siempre apelando a la imaginación del lector cuando se trataba de delitos aberrantes. Aún no se practicaba el "amarillismo" y parecía ser de mal gusto hablar de la sordidez de la vida cotidiana en las clases más bajas.

De tal manera que la precariedad social en los ámbitos rurales, si bien era suficientemente "supuesta" entre la población urbana, no tenía por entonces difusión periodística. Salvo la denuncia o el reclamo humanitario

25 Datos tomados de las Memorias de gobierno de José Castells correspondientes a los años 1934, 1935 y 1936. 
que se hacía siempre en términos generales por algunos periodistas que escribían en medios de orientación socialista, poca atención se prestaba, por ejemplo, a los altos índices de homicidios registrados en el Chaco de aquella época. De hecho, estos datos aunque presumibles, eran desconocidos en su real magnitud por el conjunto de la sociedad.

De todos modos, con mayor o menor grado de conocimiento sobre esta realidad, tanto para el gobierno como para la sociedad en general no parecía representar un problema demasiado preocupante, puesto que entonces se asumía casi como algo natural que estos episodios ocurriesen dentro del componente social y el contexto en que se producían.

De ahí que a nivel gubernamental las medidas supuestamente correctivas a esta situación carecieron del impulso necesario, de sentido común y, por lo tanto, de efectividad. Las disposiciones restrictivas, como las del "sábado inglés", o las prohibiciones de algunos entretenimientos potencialmente inductores de conflictos no podían ser más que pretensiones idealistas, ya que no se contaba con una estructura policial capaz de implementar estos controles en los ámbitos rurales.

Por otro lado, y tal vez en parte por los motivos expuestos, desde el gobierno local hubo una fuerte tendencia a minimizar o relativizar las altas tasas de delitos contra las personas publicadas por la propia gobernación, apelando al atenuante de que frente al continuo incremento poblacional, estas cifras no aumentaban, sino que en realidad, decrecían. El empeño puesto por algunos gobernadores para mejorar la imagen del Chaco a nivel nacional, prevalecía sobre la necesidad de sincerar el diagnóstico sobre las críticas deficiencias del control social en el Territorio. ${ }^{26}$

Pero paradójicamente, al mismo tiempo en que desde el gobierno se "naturalizaban" estos elevados índices y se presentaba una maquillada imagen de la situación social del Chaco en Memorias de Gobierno y discursos, por vía administrativa se clamaba insistentemente ante los poderes centrales por un aumento en las plazas policiales. Como otra paradoja cabe señalar que entre los argumentos de mayor peso que se utilizaron para justificar estos pedidos, prevalecían más los que aludían a la falta de garantías para la propiedad particular (muy razonables en determinados momentos), que aquellos que evidenciaban la vulnerabilidad personal de los habitantes rurales.

26 Al respecto pueden verse las citadas Memorias de Gobierno de José Castells de 1934 a 1936 y también las de su sucesor en el gobierno, Gustavo Lagerheim, correspondientes al periodo 1938-1941. 
De todas formas, el despertador de los dirigentes nacionales sobre algunos aspectos de la cuestión social en el Chaco sonaría a partir de los sucesos del llamado movimiento agrario de $1936,{ }^{27}$ el cual por su virulencia y repercusión extra-regional, obligó a los poderes centrales a colocar entre las prioridades la búsqueda de soluciones de fondo para mejorar el control social en este Territorio, y sopesar eventuales reformas institucionales para estos espacios.

Dichos sucesos, combinados con las noticias de un alarmante incremento de las actividades delictivas en esta jurisdicción, ${ }^{28}$ reimpulsarían precisamente en este año el reiteradamente postergado debate sobre la creación de una fuerza especial de seguridad para el conjunto de los Territorios Nacionales. La discusión sobre el tema se prolongaría durante los meses subsiguientes, hallando resultados concretos a mediados de 1938 cuando se dispuso la organización de una nueva institución de control estatal destinada específicamente a estos espacios territoriales. ${ }^{29} \mathrm{El} \mathrm{Chaco,} \mathrm{en} \mathrm{este} \mathrm{senti-}$ do, había oficiado de laboratorio de ensayo para medir los alcances y consecuencias de un esquema de colonización intensiva.

27 El movimiento agrario de 1936 fue la continuación de un conflicto iniciado en el interior del Chaco en 1934 y liderado por una asociación que tuvo actuación en otras regiones del país, autodenominada Junta de Defensa de la Producción y de la Tierra. Esta agrupación, que inicialmente tuvo el propósito de mejorar los precios que se pagaban al colono por el algodón, promovió las huelgas más conflictivas de esta década en el Chaco. Para 1936 las motivaciones de esta Junta adquirieron un tinte fuertemente político y la metodología de intimidación puesta en práctica la convirtieron en una agrupación radicalizada y resistida por sus supuestos seguidores y por la comunidad en general. Sus acciones violentas, que llegaron a hacer peligrar la campaña algodonera de ese año, terminaron cuando el gobierno local ordenó la represión del movimiento y la detención de sus principales dirigentes. No obstante, la efervescencia laboral producida por el conflicto, que llegó motivar la intervención y visita al Chaco de legisladores nacionales, sirvió de aliciente —entre otros motivos- para que los poderes centrales reimpulsaran proyectos de creación de nuevas instituciones de control social.

28 Durante el primer tercio de la década del treinta comenzó a difundirse en el Chaco el fenómeno del bandolerismo rural. El mismo, que se presentó también en otros Territorios Nacionales de la Argentina por la misma época, tuvo como característica especial en el Chaco una vigencia que se mantuvo durante toda esa década, la espectacularidad de los asaltos y secuestros y los montos recaudados por bandoleros que, a consecuencia de sus correrías, terminaron convirtiéndose en verdaderos mitos hasta el día de hoy.

29 El 23 de julio de 1938 se sancionó la ley de creación de la actual Gendarmería Nacional. Entre los argumentos más recurrentes que se esgrimieron en los debates, sobresalieron los que aludían a la inseguridad e indefensión de los pobladores rurales de los Territorios Nacionales, particularmente en el Chaco. De hecho, esta fuerza instaló su primer regimiento en este Territorio que por entonces era considerado como el menos seguro del país y fue en el área rural de Sáenz Peña (segunda ciudad en orden de importancia en el Chaco) donde comenzó a ejecutar sus primeras operaciones. 


\section{Algunas consideraciones finales}

Uno de los rasgos más notables que identificó al Chaco ante la sociedad argentina durante varias décadas fue precisamente su condición de espacio inhóspito y hostil a la civilización blanca, ya que los intentos para incorporar esta región habían fracasado en reiteradas oportunidades desde la época colonial.

Una intrincada geografía con cerrados bosques vírgenes; un clima subtropical tórrido, muy seco o muy húmedo según las zonas; y sobre todo, parcialidades indígenas guerreras y nómadas, se habían combinado para impedir que este espacio territorial fuese conquistado por los blancos. De hecho, este vasto territorio fue el último en ser incorporado al Estado Argentino luego de sucesivas campañas militares que sometieron a los naturales y efectivizaron la conquista entre la primera y segunda década del siglo $\mathrm{XX}$.

De modo que para el imaginario colectivo de la sociedad nacional, por los motivos expuestos, pero especialmente por las sangrientas alternativas de la lucha contra el indígena, el Chaco había quedado registrado como sinónimo de salvajismo y adversidad. Esta idea, sostenida durante el ciclo forestal debido a las pésimas condiciones laborales que supuso el permisivo sistema de explotación, se mantuvo viva incluso cuando durante la segunda etapa de poblamiento, el ingreso inmigratorio y el éxito en el cultivo algodonero convirtieron al Chaco en un polo de atracción, pleno de oportunidades para el progreso.

Es que la propia dinámica del ciclo algodonero terminó desbordando la estructura funcional del Territorio creada para épocas anteriores, imposibilitando la adaptación en tiempo y forma de un adecuado esquema reemplazante que permitiera ciertas garantías básicas a esta sociedad en proceso de formación.

De allí que, a través de repentinos espasmos de disconformidad y/o incremento de los índices delictivos, se manifestaran claramente las deficiencias del Estado en la atención de esta sociedad nueva que evolucionaba vertiginosamente en número de habitantes y también en demandas. A la sazón, algunos de los problemas sociales de esta etapa trascendieron el

30 Fragmento del discurso pronunciado por el gobernador José Castells en la flamante emisora local de Resistencia (capital del Chaco), en 1933. Publicado en el Boletín Oficial de la Gobernación, n. ${ }^{\circ} 3$, correspondiente al año 1933, pág. 17. 
marco regional y cuando ciertos episodios virulentos llegaron a las páginas de la prensa nacional, resurgió la imagen del Chaco como un sitio lejano, hostil, y al margen de los controles estatales.

De hecho, el propio gobernador Castells supo reconocer en uno de sus iniciales discursos como funcionario, la idea que se tenía respecto a este Territorio:

“...Cuando vine al Chaco por primera vez, hace más de diez años, recibí una sorpresa inmensa. El Chaco no era lo que yo había leído en los libros; el Chaco no era lo que decían las estadísticas viejas; el Chaco era mucho más que lo que yo había escuchado...Era un Territorio admirable, lleno de vida y de pujanza; mucho más rico y civilizado que lo que dicen las referencias de gente que pasó por éste sin comprenderlo... Viví en el Chaco mucho tiempo, y cuando iba a Buenos Aires y refería lo que era esto a amigos inteligentes, la mayoría de las veces se me escuchaba con manifiesta incredulidad. Allá en el sur, en la gigantesca capital, nadie cree la verdad del Chaco....".30

Pero al margen de las distorsiones entre el imaginario nacional y la realidad local, lo concreto es que los registros estadísticos, los testimonios orales y la información oficial y periodística ofrecen pruebas irrefutables de la situación de precariedad en la que se desenvolvió, al menos una parte de esta sociedad aluvional. Esta vulnerabilidad se evidenció con particular claridad en los espacios rurales, en donde la distancia, el componente humano involucrado en las tareas propias del campo, y otros condicionantes antes comentados hicieron dificultosos los intentos de un control social acorde a la masa humana afluyente como consecuencia del fenómeno algodonero.

Las acciones del Estado para mitigar esta problemática consistieron durante varias décadas en medidas coyunturales al efecto (creación de efímeros cuerpos de seguridad, como las diferentes y sucesivas gendarmerías; comisiones reguladoras, como por ejemplo la Comisión de Braceros; autorización para la instalación de destacamentos policiales privados, etcétera) que cumplieron temporalmente funciones de control social. Mientras pudo, el Estado Nacional se desligó de ciertas responsabilidades como garante del orden, o en su defecto las transfirió de hecho, en tanto ciertas situaciones no se desbordaran y el aporte rentístico del Chaco al erario público y el patrimonio de ciertas empresas aquí instaladas no estuviesen en riesgo.

Esta actitud se modificaría sin embargo hacia la segunda mitad de la década del treinta, cuando ante la repetición o incandescencia de ciertos conflictos y la escalada en los índices de delitos contra la propiedad y las 
personas, los poderes centrales se vieron urgidos a considerar la creación de otras instituciones de seguridad o contención, e implementar nuevas formas de control social para estos espacios periféricos.

A partir de entonces comenzaron a cimentarse las bases de una modificación institucional de fondo para los Territorios Nacionales de la Argentina. La provincialización posterior de algunos de ellos sería la resultante de los debates generados precisamente en este momento, los que a la sazón habrían de servir para completar, en un plazo relativamente breve, la inserción definitiva y con plenos derechos de estas jurisdicciones y sus sociedades a la Nación organizada.

Recibido el 30 de enero de 2008 Aceptado el 4 de noviembre de 2008 